\title{
Interhemispheric transmission of information: Measurement in normal man
}

\begin{abstract}
MORRIS MOSCOVITCH and JACK CATLIN, University of Pennsylvania, Philadelphia, Pa. 19104
\end{abstract}

$A$ reaction-time experiment assessed the time taken for information to pass from one cerebral hemisphere to the other in man. The experiment yielded a value on the order of $10 \mathrm{msec}$, consistent with available electrophysiological findings. The results also suggest that the reaction-time paradigm can be used to assay cerebral dominance for speech.

Recent work on patients suffering from lesions of the cerebral cortex has generated new interest into the localization of function and its implications for physiological mechanisms of cognition (Sperry, 1968; Milner, 1967; Geschwind, 1965). Work on normals can extend and elaborate these findings. The present paper reports one investigation along these lines.

Human patients who suffer damage to the dominant (generally the left) cerebral hemisphere often show speech disturbances (Penfield \& Roberts, 1959). Data from patients who have undergone section of the corpus callosum (Sperry \& Gazzaniga, 1967) and results from intracarotid injections of sodium amytal (Milner et al, 1966; Wada \& Rasmussen, 1960) confirm this localization. Usually, only the left hemisphere can speak, the right being mute. Information that goes to the nondominant hemisphere must be shuttled across interhemispheric paths to the dominant side before a $\mathrm{S}$ can speak about it. This would suggest that verbal reaction times in normal Ss should be shorter for stimuli flashed to the visual half-field projecting to the dominant hemisphere than for those presented in the opposite half-field. Electrophysiological studies (Bremer, 1958; Grafstein, 1959; Teitelbaum et al, 1968) show that excitation originating exclusively in one hemisphere takes approximately $10 \mathrm{msec}$ (primary positive wave) to $35 \mathrm{msec}$ (secondary negative wave) to cross the corpus callosum and its related synapses to the opposite hemisphere. Any difference in verbal reaction times to stimuli in different visual half-fields therefore should be of this order. We have verified this prediction.

Two recent similar experiments failed to demonstrate the anticipated effect (Brindley et al, 1967; Hirata \& Osaka, 1967). This failure, however, may have reflected procedural flaws rather than an incorrect hypothesis. The response required of the Ss in both experiments was a gross movement of the dominant hand. Except for the fingers, both hemispheres may control each hand. It, therefore, is understandable that no differences in reaction times emerged to stimuli presented to opposite visual fields. Other possible sources of error existed in each experiment. Brindley et al (1967) projected the stimuli, at most, $2.5 \mathrm{deg}$ off the fovea; thus, the possibility remained that stimuli intended for only one hemisphere frequently went to both. Hirata \& Osaka (1967) exposed stimuli for $200 \mathrm{msec}$. Their Ss had ample time to shift their gaze off the fixation point and onto the stimulus. In addition, their Ss had to coordinate their manual responses with appropriate verbal responses. Consequently, Hirata and Osaka obtained unusually long reaction times. This source of increased variance could have masked the expected difference.

Earlier experiments were more promising. Poffenberger (1965), in 1912, apparently demonstrated the effect. His Ss, however, were quite sophisticated and may have given biased results. Smith's (1947) experiments are confusing. He obtained large differences (50 $\mathrm{msec})$ between crossed and uncrossed reaction times in normals but failed to obtain such differences in split-brains. His experiments, however, suffer from the methodological flaws mentioned above as well as from some additional ones of his own. Jones \& Jones (1947) claimed success, but, unfortunately, their report is very limited and does not state the size of the reaction-time difference.

The present study avoided the methodological flaws committed by Brindley et al and by Hirata and Osaka. We used a rear-screen stimulus projector (Series 80, Industrial Electrical Engineers, Inc.), modified to present letters. A black wooden display panel had one rectangular opening on the left and another on the right. Each opening was $8.9 \mathrm{~cm}$ high and $14 \mathrm{~cm}$ wide. The stimulus projector could be eased forward into either opening until its screen was flush with the front of the panel. The inner borders of the openings were $35.6 \mathrm{~cm}$ apart. When the $\mathrm{S}$ viewed material in the left opening, he fixated a $.6 \mathrm{~cm}$-diam hole that lay $7.6 \mathrm{~cm}$ from its inner border. A similar fixation point was provided for the display opening on the right.
Twelve capital letters, $\mathrm{A}, \mathrm{H}, \mathrm{I}, \mathrm{M}, \mathrm{O}, \mathrm{S}$, $\mathrm{U}, \mathrm{V}, \mathrm{T}, \mathrm{X}, \mathrm{Y}$, and $\mathrm{Z}$, were chosen for their symmetry about the vertical axis to serve as stimuli. Each letter was $5.4 \mathrm{~cm}$ high and, depending on the letter, 1.6 to $6.0 \mathrm{~cm}$ wide. The letters appeared white on a dark-grey background. The $\mathrm{S}$ was seated $1.7 \mathrm{~m}$ from the display panel. Thus, the inside of each letter fell at least $4.2 \mathrm{deg}$ off the fovea of the $S$. This insured that the stimuli projected exclusively to the intended hemisphere. The choice of material, combined with the method of presentation employed, eliminates the possibility of either a reading bias or an attention bias in favor of one of the visual fields (Bryden, 1964; Heron, 1957).

The $S$ fixated binocularly the appropriate hole upon a warning signal. It was not necessary to control or monitor further the S's eye movements since it has been established that a person can maintain fixation quite easily during the time required for this experiment (Riggs et al, 1954). The $E$, seated behind the display panel, looked through the small hole and determined that the $S$ was appropriately fixating. The $E$ then activated a switch that started a $100-\mathrm{msec}$ presentation of a letter and simultaneously activated a timer (Type MST 500, Standard Electric Co.). The $S$ had to name the letter as quickly as he could. His response was picked up by a crystal microphone $30 \mathrm{~cm}$ in front of him. The microphone output operated a voice relay (Kinematix, Inc.) that stopped the timer. The timer was accurate to $\pm 1 \mathrm{msec}$.

Each $S$ received 900 trials. The different letters came randomly over these trials. Trials were grouped into blocks of 30 . For each block, the letters were presented to only one visual field. A trial occurred approximately every $30 \mathrm{sec}$. Ss sometimes incorrectly identified a letter or made a sound unrelated to its proper pronunciation. In such cases, even though the $S$ always immediately and spontaneously corrected himself, the mistake was recorded, the trial was discarded, and the letter was reinserted at some later point during that block.

Each $S$ served in five sessions, with six blocks per session. The order of blocks within a session was random within the following constraints: Blocks occurred in three pairs, each pair containing one block of stimuli to the left visual field and the other to the right; no $S$ received the same sequence of blocks twice during the five sessions, and the order of blocks over the five sessions differed as much as possible from $S$ to $S$. During presentation of a block, the $S$ was permitted to speak only in order to identify a letter; between successive pairs of blocks, he received a rest of approximately $5 \mathrm{~min}$. 
The Ss were six males and three females ranging in age from 18 to 21. All were experimentally naive. We wanted to select only right-handed $S s$, since the overwhelming majority of them have left hemispheric dominance (Milner et al, 1966). Such a selection procedure provides an independent measure of dominance. Consequently, at the beginning of the experiment, each $\mathbf{S}$ wrote his name and telephone number on a piece of paper. We used this single initial crude test for handedness since we feared that any further tests or questions about handedness could turn our naive Ss into enlightened ones. At the end of the experiment, each $\mathbf{S}$ was questioned to determine his handedness (Satz et al, 1967; McRae et al, 1968) and his degree of knowledge about the experiment. None of the Ss, though prodded, had even a vague idea of what the experiment was about. Each $S$ was also given three conventional tests of eye dominance.

The results of the tests of handedness and eye dominance appear in the second and third columns of Table 1. Reaction times were on the order of $400 \mathrm{msec}$. The last three columns of Table 1 contain data on the critical differences in reaction times. The median reaction time for each block was calculated, and the difference between the right and left medians within each block pair was computed. For each $S$, a one-tailed Wilcoxon matched-pair sign-rank test was applied to the 15 block-pair differences to determine the significance level of the right-visual-field advantage. Six of the seven right-handed Ss reacted significantly faster to material presented to the right visual field. Neither ambidextrous $S$ showed a consistent effect. For each $S$, we also obtained overall medians for reaction times to all stimuli presented to the left visual field and to all presented to the right visual field. The differences between these overall medians (median reaction time to stimuli in the left visual field, $M d n_{L}$, minus that for the right, $M d n_{R}$ ) appear in the fifth column of Table 1. The median of these differences for right-handed Ss is $10 \mathrm{msec}$. This value is very nearly identical to the results of electrophysiological determination of the time taken for information to cross from one hemisphere to another. Although we do not wish to make too much of this remarkable agreement, it suggests that the initial positive wave of the electrophysiological transhemispheric response carries the relevant information between hemispheres. In any case, we are satisfied that the median difference in reaction time is of the right order of magnitude.

Table 1

Eye Dominance. Handedness, and Reaction Time Difference Results, by Subject

\begin{tabular}{|c|c|c|c|c|c|}
\hline Subject & $\begin{array}{c}\text { Eys } \\
\text { Dominance }\end{array}$ & Handedness & $\begin{array}{l}\text { Visual } \\
\text { Field } \\
\text { Favored }\end{array}$ & $\begin{array}{c}\text { Overall Median } \\
\text { Difference } \\
\text { (MdnL-MdnR) } \\
\text { in Misec }\end{array}$ & $\begin{array}{l}\text { Significance } \\
\text { Level of Right } \\
\text { Visual Field } \\
\text { Advantage }\end{array}$ \\
\hline C. H. & Right & Right & Right & 17 & .001 \\
\hline B. A. & Mixed & Right & Right & 10 & .06 \\
\hline E. C. & Left & Right & Right & 7.5 & .05 \\
\hline A. D. & Right & Right & Right & 24.5 & .005 \\
\hline M. Y. & Right & Right & Right & 14 & .02 \\
\hline J. T.* & Right & Right & Right & 6 & .03 \\
\hline D. G. & Right & Right & Left & -4.5 & $-* *$ \\
\hline R. M. & Mixed & A mbidex & Right & 4.5 & $.151^{* * *}$ \\
\hline D. B. & Right & Ambidex & Right & 4.5 & $.151 * * *$ \\
\hline
\end{tabular}

* J. T, had to be run an extra day since she did not follow the instructions well on the first day. * As this S's data opposed the predicted result, no p-value is assessible under the one-tailed test used. *** For ambidextrous $S \mathrm{~s}$ hemispheric dominance is not strongly predicted, making the one-tailed test not strictly applicable. Note that even with its benefit, neither R.M.'s nor D.B.'s results approach significance.

These results cannot be explained as a consequence of eye dominance (Minucci \& Connors, 1964); of the six Ss who favoied the right visual field, two were not right-eye dominant. The pattern of mistakes made in identifying the letters also cannot explain our results. Such an account would assume that mistakes cause an increase in reaction time on subsequent trials. In fact, three Ss who favored the right visual field made equal numbers of mistakes to material presented to each field. The only explanation, other than interhemispheric crossing time, that might account for our data is that the dominant hemisphere is more efficient than the other in processing visually presented verbal material (Zurif \& Bryden, 1969). A test between the two explanations will be necessary in subsequent work.

Our results indicate that six of our seven right-handed Ss are left-brain dominant. This proportion agrees with tests of dominance using the Wada technique and with Milner's (1967) and Kimura's (1961) data. Accordingly, our reaction-time test may be a useful measure of dominance.

We also analyzed the errors made by the six right-handed Ss who favored the right visual field. They had more difficulty in identifying letters presented to the left visual field than in identifying those presented to the right $\left(\chi^{2}, 1 \mathrm{df}, \mathrm{p}<.05\right){ }^{2}$ This observation agrees well with bryaen s (1965) findings. Mistakes could be classified into two groups: slurs,

Table 2

Relative Numbers of Visual and Auditory Confusions, by Visual Field, for Subjects Favoring the Right Visual Field

\begin{tabular}{lccc}
\hline & $\begin{array}{c}\text { Left } \\
\text { Visual } \\
\text { Ficld }\end{array}$ & $\begin{array}{l}\text { Right } \\
\text { Visual } \\
\text { Iield }\end{array}$ & Total \\
\hline Visual Confusions & 17 & 8 & 25 \\
Auditory Confusions & 3 & 3 & 6 \\
\hline
\end{tabular}

hesitations, stutters, and mispronunciations, as opposed to clear confusions between letters. Most of the errors fell in the former category. An analysis of the confusion errors was done to ascertain whether they were primarily auditory or visual. We selected five pairs of letters, V-U, V-Y, V-X, X-Y, X-Z, confusable primarily along visual lines, and five pairs of letters, A-H, I-Y, X-S, H-S, $\mathrm{H}-\mathrm{X}$, confusable primarily along auditory lines. We tabulated the number of confusions within both the visual and auditory sets of pairs. These data, broken down by visual fields, appear in Table 2. The total number of visual confusions was significantly greater than the total number of auditory confusions $\left(\chi^{2}, 1 \mathrm{df}, \mathrm{p}<.01\right)$.

We can conciude that our task strains the visual-processing mechanism. The low rate of auditory confusions need not challenge the current theory (Sperling, 1967) that visually presented verbal material must be recoded into an auditory form before articulation. The capacity of the auditory-processing mechanism may be so large that our reaction-time task imposes little demand on it. Finally, Table 2 also shows that visual confusions occur primarily to stimuli presented to the left visual field, whereas auditory confusions occur equally often in both visual fields. The predominance of visual confusions in the left visual field, though only marginally significant $\left(\chi^{2}, 1 \mathrm{df}, \mathrm{p}<.1\right)$, suggests that information is transferred to the dominant hemisphere in a visual code.

\section{REFERENCES}

BREMER, F. Physiology of the corpus callosum. Research Publications of the Association for Nervous \& Mental Diseases, 1958, 36, 424-448.

BRINDLEY, G. S., CARPENTER, R. H. S., \& RUSHTON, D. N. Reaction times for simple shape discriminations requiring one or both visual fields. Quarterly Journal of Experimental Psychology, 1967, 19, 70-72. 
BRYDLX. If. P. Iathstereopic reegrition and cerebral dominance. Perceptual \& 110 tor Skills, 1964.19 .686$.

BRYDEN. II. P. Tachistoseopic recoonition, handedness, and cerebral dominance. Neuropsychlogia, 1965, 3, 1-8.

GESCHWIND, N. Disconnexion syndromes in animals and men. Brain, 1965, 88, 585-644.

GRAFSTEIN, B, Organization of callosal connections in supra-sylvian gyrus of cat. Journal of Neurophysiology, 1959, 22, 504-515.

HIRATA, K., \& OSAKA, R, Tachistoscopic recognition of Japanese letter materials in left and right visual fields. Psychologia, 1967, 10, 7-18.

HERON, W. Perception as a function of retinal locus and attention. American Joumal of Psychology, 1957, 70, 38-48.

JONES, M. H., \& JONES, F. N. The relationship of verbal reaction time to hemisphere of entry of a visual stimulus. American Psychologist, $1947,2,408$.

KIMURA, D. Cercbral dominance and the perception of verbal stimuli. Canadian Joumal of Psychology, 1961, 15, 166-171.

McRAE, D. L., BRANCH, C. L., \& MILNER, B. The occipital horns and cerebral dominance. Neurology, 1968, 18, 95-98.

MILNER, B. Brain mechanisms suggested by studies of temporal lobes. In C. H. Millikan and F. L. Darley (Eds.), Brain mechanisms underlying speech and language. New York: Grune \& Stratton, 1967

MILNER, B., BRANCH, C., \& RASMUSSEN, T. Evidence for bilateral speech representation in some non-right-handers. Transactions of the American Neurological Association, 1966, 91 306-308.

MINNUCI, P. K., \& CONNORS, M. M. Reaction time under three viewing conditions: Binocular, dominant eye, and non-dominant eyc. Journal of Experimental Psychology, 1964,67, 268-275.

PENFIELD, W., \& ROBERTS, L. Speech and brain mechanisms. Princeton: Princeton University Press, 1959.

POFFENBERGER, A. T. Cited in E. G. Ettlinger (Ed.), Functions of the corpus callosum. Boston: Little, Brown, 1965. P. 101.

RIGGS, L. A., ARMINGTON, J, C., \& RATLIFF, F. Motions of the retinal image during fixation. Joumal of the Optical Society of America, 1954,44, 315-321.

SATZ, P., ACHENBACH, K., \& FENNEL, E. Correlations between assessed manual laterality and predicted speech laterality in a normal population. Neuropsychologia, 1967 , 5, 295-310.

SMITH, K. U. Bilateral integrative action of the cerebral cortex in man in verbal association and sensory motor co-ordination. Joumal of Experimental Psychology, 1947, 37, 367-376.

SPERLING, G. Successive approximations to a model for short term memory. Acta Psychologia, 1967, 27, 285-292.

SPERRY, R. W. Hemispheric deconnection and unity in conscious awareness. American Psychologist, 1968, 23, 723-733.

SPERRY, R. W., \& GAZZANIGA, M. S. Language following surgical disconnection of the hemispheres. In C. H. Millikan and F. L. Darley (Eds.), Brain mechanisms underlying speech and language. New York: Grune \& Stratton, 1967.

TEITELBAUM, H., SHARPLESS, S. K., \& $B Y C K, R$. Role of somatosensory cortex in interhemispheric transfer of tactile habits. Journal of Comparative \& Physiological Psychology, 1968, 66, 623-632.

WADA, J, \& RASMUSSEN, T, Intracarotid injection of sodium amytal for the lateralization of cerebral speech dominance: Experimental and clinical observations. Journal of Neurophysiology, 1960, 17, 266-282.

ZURIF, E. B., \& BRYDEN, M. P. Familial handedness and left-right differences in auditory and visual perceptions. Neuropsychologia, 1969, 7, 179-187.

\section{Structure and short-term memory ${ }^{1}$}

\section{WILLIAM A. STOCK, Iowa State University, Ames, Iowa 50010}

Fifty-six undergraduates participated in a probe experiment investigating the effects of list structure and rate of presentation on recall. Very strong serial-position effects were found, with structured lists exhibiting higher recall and a von Restorff effect. Rate of presentation did not result in significant differences.

A theory of immediate memory has been proposed (Waugh \& Norman, 1965; Norman, 1966). This is a two-store theory, composed of a limited-capacity short-term memory (STM) and a long-term memory (LTM). "Rehearsal," i.e., attending to an item in order to increase its strength, preserves items in STM and makes it possible for an item to make the transition to LTM. All items in STM have the same probability of making the transition to LTM; therefore, if rehearsal is restricted to only the most recently presented item, the longer an item is in STM, the less its chances are for transition. The Waugh and Norman model accounts for serial-position (SP) effects in a method of their invention, the probe method. This technique generates a monotonic SP curve, with probability of correct recall a function of the number of items intervening between the to-be-recalled (critical) item and the occurrence of the probe at the end of the list. The critical item is the item following the first occurrence of the probe. Items furthest from the end of the list are recalled poorest.

Another theory, Feigenbaum \& Simon's (1962), is based on the supposition that persons act as information-processing systems. The most relevant aspect of their theory to the present study is the anchor-point hypothesis. That is, a memory processor locates anchor points in the stimuli stream and processes the stimuli items by "tying them" to these anchor points. In homogeneous lists, it is most likely that the two ends of the list provide the anchor points.
NOTES

1. Supported by NSF Grant GB-8013 to Dr. Paul Rozin. We are grateful to Dr. Burton Rosner and Dr. Paul Rozin for advice, criticism, and

2. Happily, the ambidextrous Śs did not show a visual field bias with respect to the number or nature of the errors they committed Like the righthanded group, however, the confusion errors the ambidextrous Ss made were primarily visual: ight visual confusions to only one auditory confusion.

In the probe paradigm, with "rehearsal" held constant, these two theories predict different results when lists are composed of two successive sets of stimulus items (half digits, half colors). The Feigenbaum and Simon theory would predict a von Restorff effect (a scallop effect at the point of bifurcation), while the Waugh and Norman theory would predict a monotonic curve. Several predictions were made in the present study. It was hypothesized that (1) unstructured lists would generate SP curves identical in nature to those reported by Norman (1966), (2) that overall recall for structured lists would be higher than for unstructured lists, (3) that the effects of rate of presentation would not differ, and finally, (4) structured lists were expected to produce a von Restorff effect at the point of bifurcation of the lists.

\section{SUBJECTS}

The Ss were 56 undergraduate volunteers, who received course credit for their participation.

\section{LISTS}

A 2 by 2 by 11 factorial design was formulated. Lists were presented in either a structured or unstructured manner and at one of two rates of presentation. The probe occurred at 11 SPs.

The stimulus populations consisted of digit words $(1,2,3,4,5,6,7,8,9,0,12)$ and color words (black, white, pink, brown, blue, tan, beige, red, green, gold, gray, orange). Zero was pronounced "oh" and orange was pronounced "ornge."

The experimental task involved listening to a stimulus list and then recalling the critical digit. Ss were able to recognize the probe only by realizing that the final item had been said. It had been explained that all lists had an equal number of items. Half the time the probe was a digit and half the time it was a color. The probe occurred at Positions 1 through 11 in the lists; the critical item could thus occur in Positions 2 through 12.

Structured lists were constructed by drawing, approximately at random, six digits and six colors from the populations. 